Supporting information

\title{
Effect of TCE concentration and dissolved groundwater solutes on NZVI-promoted TCE dechlorination and $\mathrm{H}_{2}$ evolution
}

Yueqiang Liu, Tanapon Phenrat, and Gregory V. Lowry*

\author{
Department of Civil \& Environmental Engineering \\ Carnegie Mellon University, Pittsburgh, PA 15213-3890, USA
}

Corresponding author: glowry@cmu.edu

412-268-2948 


\section{Assumed NZVI-promoted TCE reaction pathways}

TCE reduction by RNIP was assumed to follow previously published reaction pathways (1), but it was assumed here that all TCE reduction occurred via $\beta$-elimination to form acetylene $\left(\mathrm{k}_{\mathrm{TCE}}\right)$, followed by acetylene reduction to ethene and ethane (Scheme SI-1). This modification was made based on the observation of a constant ratio of ethene to ethane formed while TCE was present, suggesting that their production was concomitant. High concentrations of TCE resulted in primarily acetylene formation $(86 \%)$, further suggesting that most TCE was dechlorinated via $\beta$-elimination through acetylene.

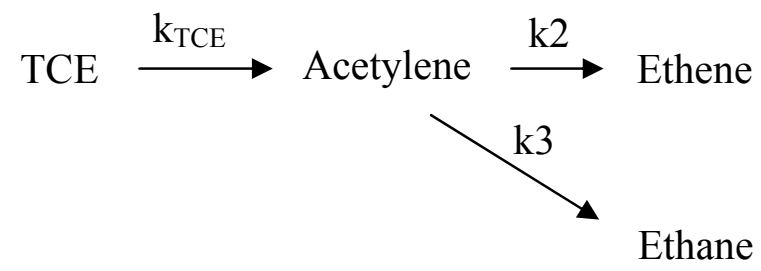

Scheme SI-1. Assumed TCE reduction pathways by RNIP

\section{Reported TCE Reaction Rate Constants}

The observed reaction rate constants, $\mathrm{k}_{\mathrm{obs}}$, in this study were adjusted and are reported as rate constants that would be observed in water without headspace (eqn SI-1) (2).

$$
k_{\text {TCE }}=k_{o b s} \frac{K_{H} V_{h}+V_{w}}{V_{w}}
$$

$K_{\mathrm{TCE}}$ and $k_{\mathrm{obs}}$ are the reaction rate constant without headspace (calculated) and with headspace (observed), respectively. $V_{\mathrm{h}}$ and $V_{\mathrm{w}}$ are the volume of the headspace and the water solution 
respectively. $K_{\mathrm{H}}$ is the dimensionless Henry's law constant for the compound. $K_{\mathrm{H}}=0.35$ was assumed for TCE at $20^{\circ} \mathrm{C} \mathrm{(3).}$

TCE degradation and formation of Reaction products and intermediates at different initial TCE concentration.

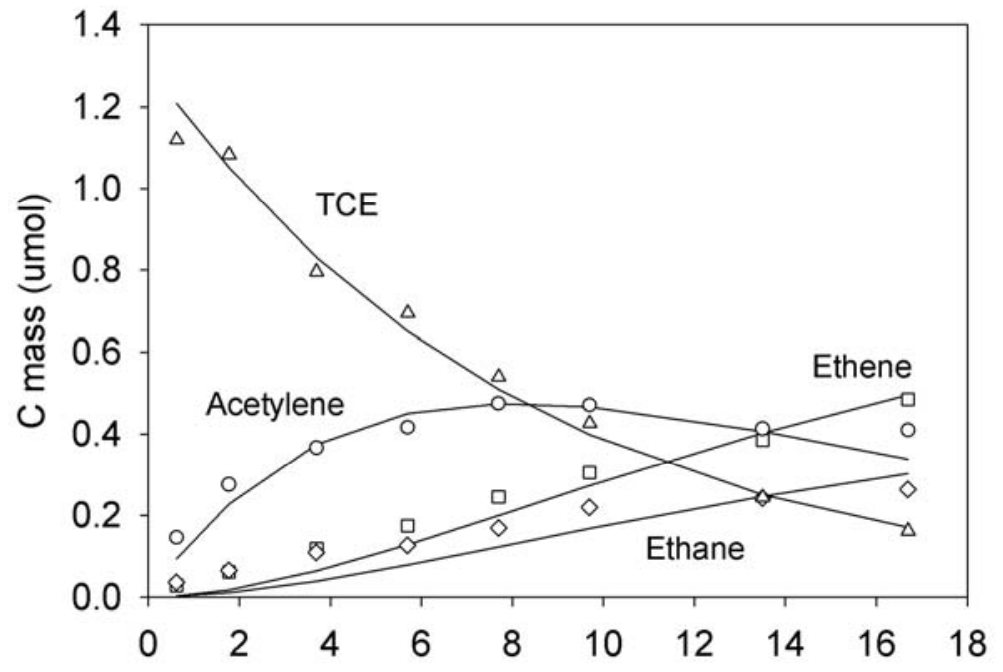

a)

Time (days)

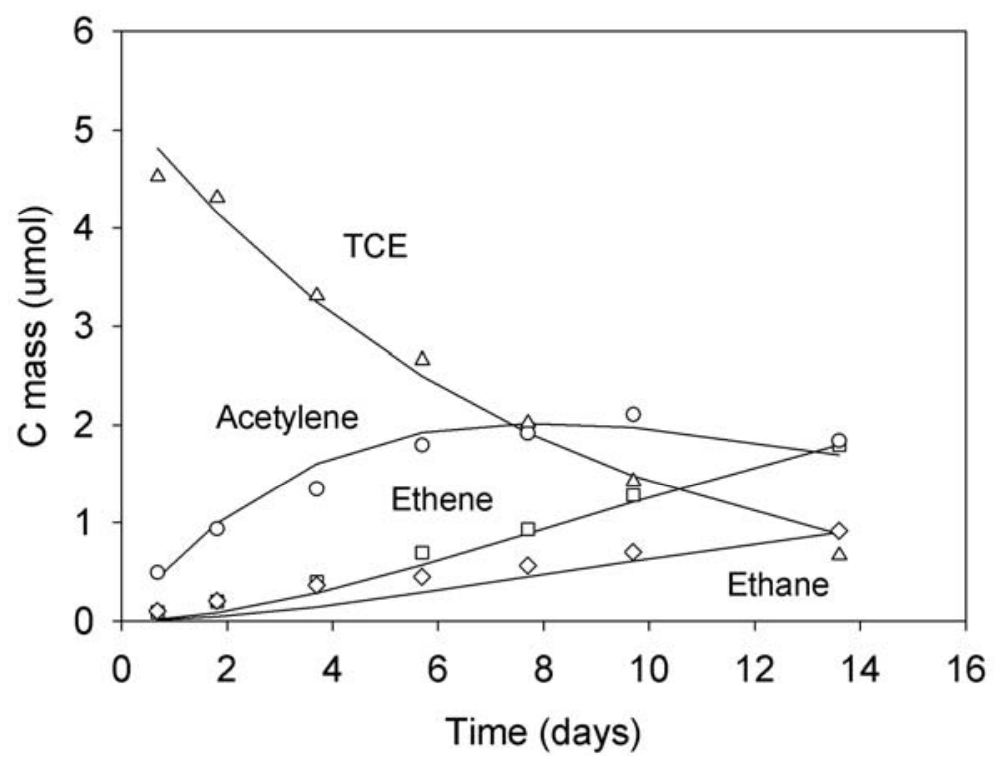




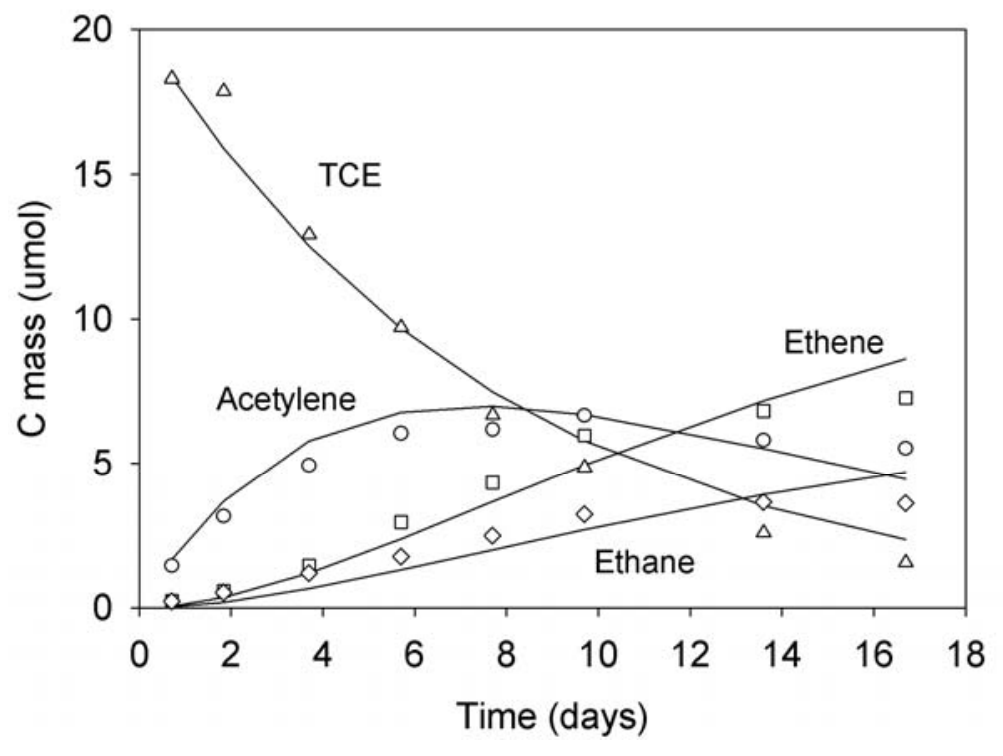

c)

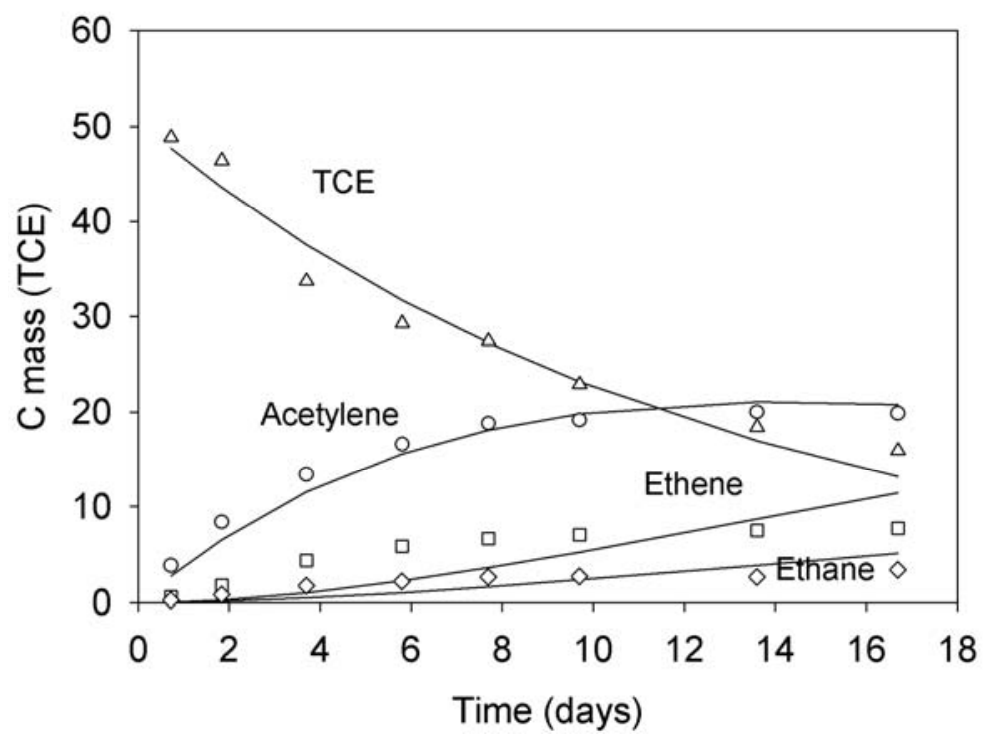




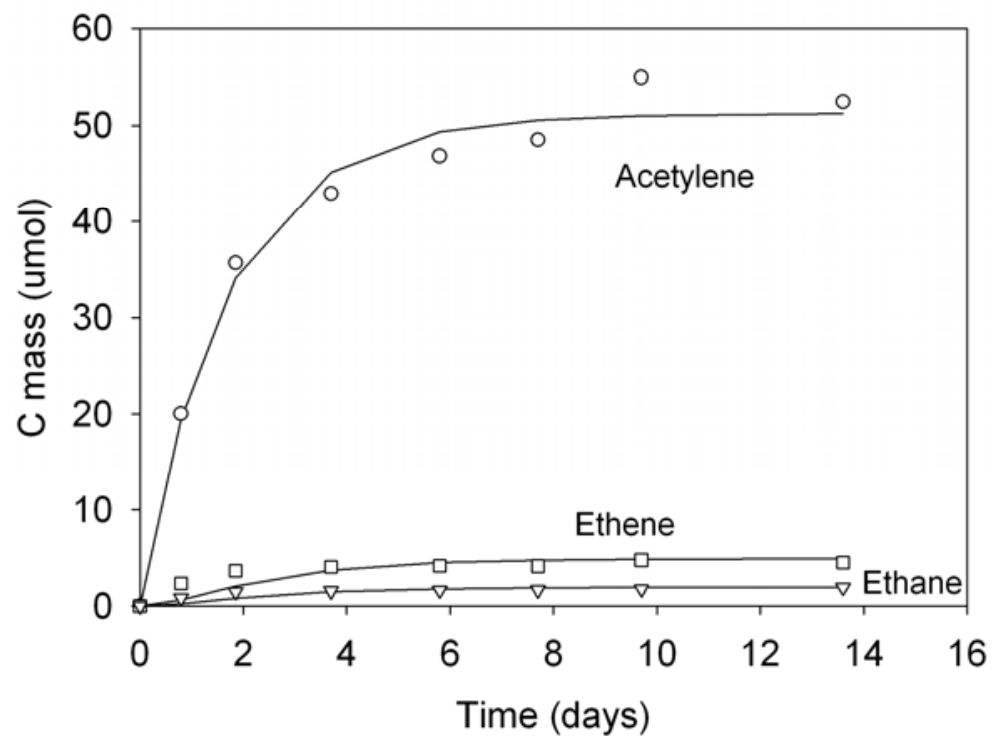

Figure SI-1. TCE disappearance and products formation at various TCE concentrations $(670 \mathrm{mg} / \mathrm{L}$ Fe48\% RNIP, $\mathrm{pH}=7.0$ buffered with 50mM HEPES); lines are a first-order fit of the experimental data. a) TCE at $0.027 \mathrm{mM}$, b) TCE at $0.11 \mathrm{mM}$, c) TCE at $0.47 \mathrm{mM}$, d) TCE at $1.3 \mathrm{mM}$, and e) DNAPL TCE (saturated TCE solution) (fitted with pseudo-first-order TCE reaction with first-order particle decay). 


\section{Derivation of Equation 1 in manuscript.}

$$
k_{\mathrm{TCE}}=\frac{a_{\mathrm{ACY}}}{C_{\mathrm{TCE}, \mathrm{S}} \cdot V_{w} \cdot C_{\mathrm{Fe}, \mathrm{SA}}}
$$

In this work, the primary TCE dechlorination pathway was presumed to be $\beta$-elimination, i.e. TCE is dechlorinated to form chloroacetylene which is subsequently dechlorinated to acetylene (eqn S1). The formation of chloroacetylene is believed to be the rate controlling step and supported by the observation that acetylene is the major intermediate detected. In general, the concentration of chloroacetylene is very low as it is rapidly reduced to acetylene when formed. So any loss of TCE via this pathway would result in nearly the same amount of increase of acetylene in the system.

$\mathrm{TCE} \stackrel{k 1}{\longrightarrow}$ ChloroACY $\stackrel{k 2}{\longrightarrow} \mathrm{ACY}$

In a system without headspace (to simply the problem)

$\frac{d[\mathrm{TCE}]}{d t}=-k_{1} \cdot[\mathrm{TCE}]$

$\frac{d[\text { ChloroACY }]}{d t}=k_{1} \cdot[\mathrm{TCE}]-k_{2} \cdot[$ ChloroACY $]$

The solution of the above equations is given in eqn S4 and S5:

$$
\begin{aligned}
& {[\mathrm{TCE}]=C_{0, T C E} e^{-k_{1} t}} \\
& {[\text { ChloroACY }]=\frac{k_{1} C_{0, T C E}}{k_{2}-k_{1}}\left(e^{-k_{1} t}-e^{-k_{2} t}\right)}
\end{aligned}
$$

Because $\mathrm{k} 2>>\mathrm{k} 1$, the solution can be simplified (eqn 6):

$$
[\text { ChloroACY }]=\frac{k_{1} C_{0, T C E}}{k_{2}} \cdot e^{-k_{1} t}=\frac{k_{1}}{k_{2}} \cdot[\mathrm{TCE}]
$$

Because the total amount of two carbon compounds is constant:

$$
[\mathrm{TCE}]+[\text { ChloroACY }]+[\mathrm{ACY}]=[\mathrm{TCE}]_{0}
$$

Therefore,

$\frac{d([\mathrm{TCE}]+[\text { ChloroACY }])}{d t}=\left(1+\frac{k_{1}}{k_{2}}\right) \frac{d([\mathrm{TCE}]])}{d t}=-\frac{d[\mathrm{ACY}]}{d t}$ 
Because $\mathrm{k} 1<<\mathrm{k} 2, \mathrm{k} 1 / \mathrm{k} 2<<1$, so $1+\mathrm{k} 1 / \mathrm{k} 2 \approx 1$

Therefore: $\frac{d([\mathrm{TCE}])}{d t} \approx-\frac{d[\mathrm{ACY}]}{d t}$

The formation of chloroacetylene was therefore not considered in the model development. Please note here no headspace was assumed.

Equation 1 does consider the partitioning of acetylene between headspace and the aqueous phase, but the consideration is implicit. Please note in equation $1, \mathrm{a}_{\mathrm{ACY}}$ is the rate of acetylene mass formation which includes acetylene mass in both the headspace and aqueous phase assuming instantaneous equilibrium between these phases. The production of acetylene mass is from TCE reduction only in the aqueous phase (no iron particles are in the headspace).

When mass production is considered, based on equation (S10)

$$
\frac{d M_{\mathrm{ACY}}}{d t}=\frac{d M_{\mathrm{TCE}}}{d t}=k_{1} \cdot[\mathrm{TCE}] \cdot V_{\mathrm{W}}
$$

When the solution is saturated with excess TCE DNAPL, the right side of equation (S11) is constant and acetylene formation is expected to be linear. As noted in the manuscript it is not linear because of particle deactivation. However, for the initial linear period of acetylene formation,

$$
\frac{d M_{A C Y}}{d t}=a_{A C Y}
$$

and,

$$
a_{A C Y}=k_{1} \cdot[\mathrm{TCE}] \cdot V_{\mathrm{w}}
$$

Substituting the surface reaction rate constant $\mathrm{k}_{\mathrm{TCE}}\left(k_{1}=k_{\mathrm{TCE}} \cdot C_{\mathrm{Fe}, \mathrm{SA}}\right)$ into equation $\mathrm{S} 13$ we get $k_{\mathrm{TCE}}$ for the linear part of the acetylene production when the solution is saturated with TCE and the concentration is constant.

$$
k_{T C E}=\frac{a_{\mathrm{ACY}}}{[\mathrm{TCE}] \cdot V_{\mathrm{W}} \cdot C_{\mathrm{Fe}, \mathrm{SA}}}
$$




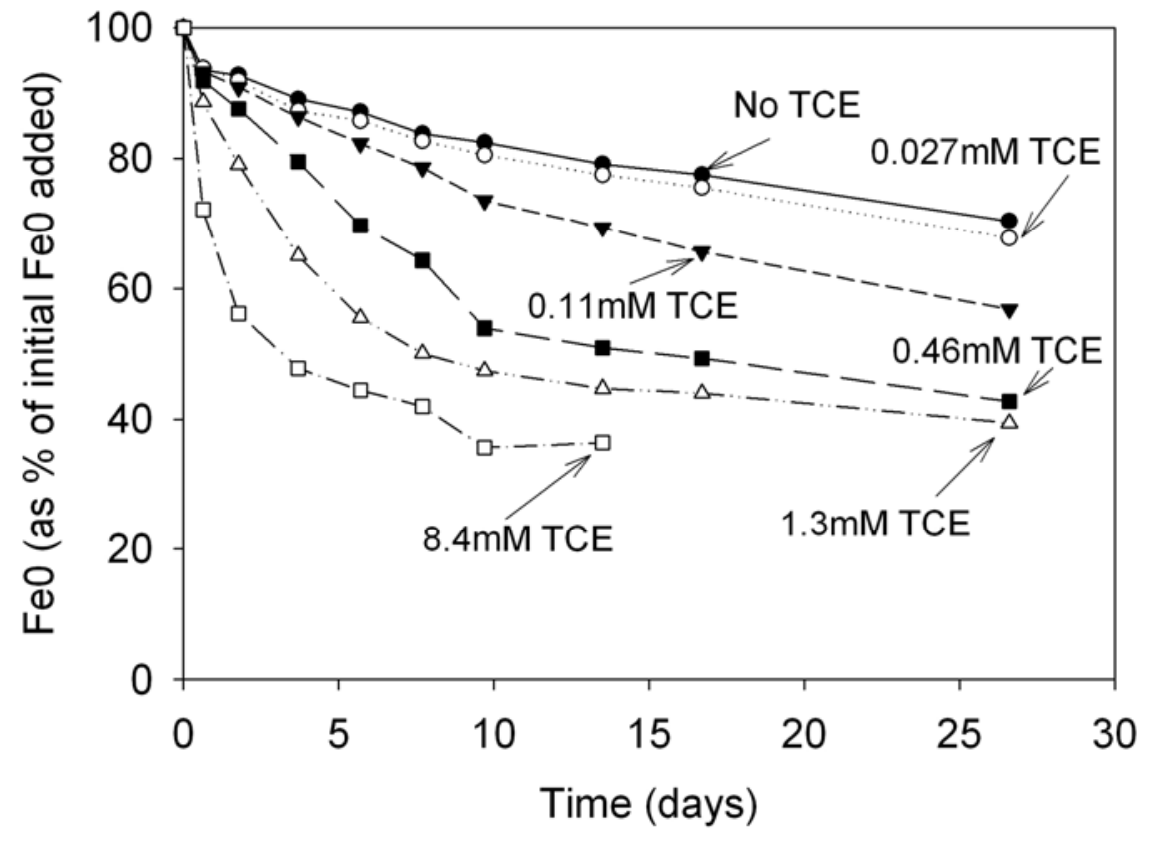

Figure SI-2. $\mathrm{Fe}^{0}$ consumption (accounting $\mathrm{H}_{2}$ evolution and TCE reduction) at various TCE concentrations $(670 \mathrm{mg} / \mathrm{L} \mathrm{Fe} 48 \% \mathrm{RNIP}, \mathrm{pH}=7.0$ buffered with 50mM HEPES). Lines are not the fit of data and used only to guide the eye. 
Table SI-1. Dissolved solutes in MI and SC groundwater and synthetic groundwater

\begin{tabular}{|c|c|c|c|c|c|c|c|c|}
\hline & \multicolumn{2}{|c|}{ SC GW } & \multicolumn{2}{|c|}{ SC SGW } & \multicolumn{2}{|c|}{ MI GW } & \multicolumn{2}{|c|}{ MI SGW } \\
\hline Parameter & $\mathbf{m M}$ & $\mathrm{mg} / \mathrm{L}$ & $\mathbf{m M}$ & $\mathrm{mg} / \mathrm{L}$ & $\mathbf{m M}$ & $\mathrm{mg} / \mathrm{L}$ & $\mathbf{m M}$ & $\mathrm{mg} / \mathrm{L}$ \\
\hline $\mathrm{Ca}^{2+}$ & 0.89 & 35.5 & 0.89 & 35.5 & 1.44 & 57.7 & 1.44 & 57.7 \\
\hline $\mathrm{K}^{+}$ & 0.04 & 1.5 & 0.04 & 1.5 & 0.01 & 0.5 & 0.01 & 0.5 \\
\hline $\mathrm{Mg}^{2+}$ & 0.45 & 10.8 & 0.45 & 10.8 & 0.50 & 12.1 & 0.50 & 12.1 \\
\hline $\mathrm{Na}^{+}$ & 6.09 & 140.0 & 6.48 & 149.0 & 0.13 & 3.0 & 2.97 & 68.5 \\
\hline $\mathrm{HCO}_{3}^{-}$ & 1.18 & 72.1 & 1.18 & 72.0 & 2.72 & 166.0 & 2.72 & 166.0 \\
\hline $\mathrm{Cl}^{-}$ & 5.32 & 189.0 & 5.32 & 189.0 & 0.31 & 11.0 & 3.78 & 134.0 \\
\hline $\mathrm{SO}_{4}{ }^{2-}$ & 1.23 & 118.0 & 1.33 & 128.0 & 0.06 & 6.0 & 0.06 & 6.0 \\
\hline $\mathrm{NO}_{3}^{-}$ & $\mathrm{ND}^{a}$ & $\mathrm{ND}^{a}$ & & 0 & 0.26 & 3.6 & 0.26 & 3.6 \\
\hline TOC & & 9.6 & & 0 & & 0.76 & & 0 \\
\hline $\mathrm{pH}$ & 6.0 & & 6.2 & & 7.9 & & 6.0 & \\
\hline
\end{tabular}

\footnotetext{
${ }^{a} \mathrm{ND}$ : non-detected, measured using ion chromatography
} 


\section{References}

(1) Liu, Y.; Majetich, S. A.; Tilton, R. D.; Sholl, D. S.; Lowry, G. V. TCE dechlorination rates, pathways, and efficiency of nanoscale iron particles with different properties, Environ. Sci. Technol. 2005, 39, 1338-1345.

(2) Tratnyek, P. G.; Scherer, M. M.; Deng, B.; Hu, S. Effects of natural organic matter, anthropogenic surfactants, and model quinones on the reduction of contaminants by zero-valent iron, Water Research 2001, 35, 4435-4443.

(3) EPA, U. S. "Engineered approaches to in situ bioremediation of chlorinated solvents: fundamentals and field applications," 2000. 